\title{
Seasonal Variation in Sex Ratios Provides Developmental Advantages in White-tailed Deer, Odocoileus virginianus
}

\author{
Sarah T. SaAlfeld ${ }^{1}$, Stephen S. DitchkofF${ }^{2}$, John J. Ozoga ${ }^{3}$, and Michael S. Mitchell ${ }^{4}$ \\ ${ }^{1}$ Arthur Temple College of Forestry and Agriculture, Stephen F. Austin State University, Nacogdoches, Texas 75962 USA \\ [Corresponding author e-mail: saalfeldst@titan.sfasu.edu] \\ ${ }^{2}$ School of Forestry and Wildlife Sciences, Auburn University, Alabama 36849 USA \\ ${ }^{3}$ N. 6383 Knox Street, Munising, Michigan 49862 USA \\ ${ }^{4}$ Montana Cooperative Fish and Wildlife Research Unit, University of Montana, Missoula, Montana 59812 USA
}

Saalfeld, Sarah T., Stephen S. Ditchkoff, John J. Ozoga, and Michael S. Mitchell. 2008. Seasonal variation in sex ratios provides developmental advantages in White-tailed Deer, Odocoileus virginianus. Canadian Field Naturalist 121(4):412-419.

Since Trivers and Willard first proposed their hypothesis concerning the adaptive advantages of producing a particular offspring sex in relation to maternal condition in 1973, it has been at the forefront of scientific research concerning sex ratios with most subsequent studies focusing on maternal condition as a key contributor to variations in sex ratios. Another factor that could greatly influence sex ratios, although has been only infrequently examined in mammalian species, is birth date. We investigated how birth date influenced offspring sex ratios in White-tailed Deer (Odocoileus virginianus). Since date of birth can greatly influence an individual's fitness and reproductive success, we suggest that birth date may be an alternative strategy in determining offspring sex ratios. Since it has been shown that the lifetime reproductive fitness of a mother can be increased by producing a particular sex during a particular time, we hypothesized that more male offspring should be born earlier in the season due to their increased reproductive potential from being born at this time. Offspring born earlier will have a head start in development and therefore have greater potential for increased body size and dominance later in life, traits that greatly influence male reproductive success. In this study, we found that maternal condition did not affect offspring sex ratio in a captive population of White-tailed Deer in Michigan; however, birth date did. We found that more males tended to be born during the second and fourth birthing periods, while more females were born during the first, third and fifth periods. In addition, we found that males born earlier in the season had greater mass the following spring than those born later, a trend that was not as dramatic in females. These results lend moderate support to our hypothesis that in White-tailed Deer offspring sex will tend to vary according to timing of birth and relative reproductive advantages gained by a particular sex being born at that time.

Key Words: White-tailed Deer, Odocoileus virginianus, birth date, early bird hypothesis, local resource competition, seasonality, secondary sex ratio, temporal variation, Trivers-Willard hypothesis.

The potential for offspring sex ratios to differ from parity has been well documented in a number of mammalian species, including White-tailed Deer (Odocoileus virginianus) (Verme and Ozoga 1981; Kojola and Eloranta 1989; Kucera 1991; Landete-Castillejos et al. 2001; Landete-Castillejos et al. 2004; Sheldon and West 2004). This strategy could enhance the lifetime fitness of a female by producing the sex with the greatest potential reproductive value. Some factors shown to influence this variation include: maternal age, condition, social status, and habitat quality. Trivers and Willard (1973) proposed that females of sexually dimorphic, polygynous species in good condition would benefit more from producing sons, because the mother's condition would more strongly influence the future reproductive success of sons than daughters. Conversely, females in poor condition would benefit most by producing daughters, since female offspring require less maternal investment (i.e., milk production) and will likely reproduce regardless of maternal condition. Poor quality male offspring likely will not develop the physical characteristics necessary to compete successfully for females later in life. Assump- tions for the Trivers and Willard hypothesis include: condition of offspring is correlated with condition of the mother after the parental investment period, condition of the young following the parental investment period will carry over to adulthood, and conditional advantages will differentially benefit male offspring in reproductive success (Trivers and Willard 1973). Since most ungulate species are polygynous, sexually dimorphic species which commonly exhibit these three assumptions (Hewison and Gaillard 1999), numerous studies have been conducted to test the Trivers-Willard hypothesis. In several of these studies, support for the Trivers-Willard hypothesis has been documented, where older or more dominant individuals gave birth to more males, and younger or subordinate females gave birth to more females (Landete-Castillejos et al. 2001; Landete-Castillejos et al. 2004; Sheldon and West 2004).

Despite the many findings that support Trivers and Willard (Landete-Castillejos et al. 2001; LandeteCastillejos et al. 2004; Sheldon and West 2004), numerous studies have reported data that seem to contradict their hypothesis. In a review of published papers on 
the genus Odocoileus, Verme (1983) found that more males were produced by younger females, females in poor condition, and females in areas of poor habitat quality. Similarly, Mendl et al. (1995) discovered that more female offspring were produced by dominant females in domestic pigs (Sus scrofa). These contradicting trends have been explained by alternative hypotheses for biased sex ratios, including: the local resource competition hypothesis (Clark 1978), the advantaged daughter hypothesis (Hiraiwa-Hasegawa 1993), and the advantaged matriline hypothesis (Leimar 1996). According to the advantaged daughter and the advantaged matriline hypotheses, mothers are better able to influence the reproductive success of daughters rather than sons (e.g., by the transfer of rank and/or access to high quality resources). Therefore, these hypotheses propose that high quality females are more likely to produce females than males. Conversely, the local resource competition hypothesis states that local resources rather than maternal condition drive biases in sex ratios. In matriarchal species, Clark (1978) proposed that females in good condition will produce more female offspring, whereas females in poor condition will invest more in male offspring. This is because female offspring normally establish home ranges that overlap their mother's home range, while males tend to disperse, creating less competition for resources in the future.

While they differ, all of these hypotheses focus on maternal condition as the driving factor in offspring sex ratios of mammals. Another factor that should greatly influence reproductive potential of offspring and offspring sex ratios is birth date. In many sexually dimorphic species, it is believed that time at birth differentially affects the ability of a particular sex to reproduce during its first and subsequent years (Suttie 1983; Clutton-Brock et al. 1984; Kruuk et al. 1999; Festa-Bianchet et al. 2000). Therefore, having biased sex ratios of offspring according to birth date could increase a female's lifetime fitness. A number of avian species have been shown to have varying sex ratios seasonally, including the Northern Goshawk (Accipiter gentiles: Byholm et al. 2002), European Kestrel (Falco tinnunculus: Pen et al. 1999), Common Sandpiper (Actitis hypoleucos: Andersson et al. 2003), American Kestrel (Smallwood and Smallwood 1998; F. sparverius: Griggio et al. 2002), Spotted Starling (Sturnus unicolor: Cordero et al. 2001), and Little Grassbirds (Megalurus gramineus: McIntosh et al. 2003). In their work with a nonmigratory population of American Kestrels, Smallwood and Smallwood (1998) found more male-biased sex ratios earlier in the season compared to later and proposed that males that fledged earlier could find nest sites and defend territories better than males that fledged later. Griggio et al. (2002) found the same results in a migratory population of American Kestrels, with more males born earlier in the season. Similarly, it was determined that the sex ratio variation could be due to acquisition of nest sites that were limited for this population. In contrast, competition for mates seemed the most likely explanation for male-biased sex ratios early in season in the Common Sandpiper, because males born earlier have an advantage in obtaining mates (Andersson et al. 2003). Although the explanations for these trends differ, they suggest that varying offspring sex ratios by birth date has an adaptive advantage to a mother by enhancing her own future fitness. Smallwood and Smallwood (1998) coined this trend the "Early Bird Hypothesis" and predicted that the sex which gains the greatest advantage by hatching earlier is selected for in early conception dates in avian species.

The Early Bird Hypothesis (Smallwood and Smallwood 1998), however, has not been evaluated in mammals. While it has been demonstrated that older individuals tend to give birth earlier (Johns et al. 1977; Festa-Bianchet 1988; Christley et al. 2002), older individuals tend to produce more male offspring (Landete-Castillejos et al. 2004), and offspring born earlier are more likely to survive due to increased food resources (Festa-Bianchet 1988; Singh et al. 1990; Festa-Bianchet et al. 1997; Côté and Festa-Bianchet 2001), the link to differential sex ratios based on birth date has not been well documented in mammalian species. We hypothesize that birth date is a driving factor in offspring sex ratios, with females producing more male offspring earlier in the breeding season and increasing production of females as the season progresses. Because offspring born earlier should have a longer period of time to grow before their first winter, more males should be produced at this time period because of the relative importance of size on future reproductive success in males and females.

\section{Materials and Methods}

We analyzed data from the Cusino enclosure, a 252-ha enclosure located near Shingleton, $46^{\circ} 21^{\prime} \mathrm{N}$, $86^{\circ} 28^{\prime} \mathrm{W}$, in Michigan's Upper Peninsula from 1973 through 1984 (excluding 1974). The enclosure consisted mainly of northern hardwoods, mixed hardwoodconifer stands, and pine (Pinus $s p$.) plantation. Due to initial overbrowsing and subsequent condition decline, deer were supplementally fed ad libitum year-round with a pelleted ration beginning in 1972 and were fed throughout the study period. Following this, deer were documented to be in good physical condition, even during winter months (Ozoga and Verme 1982). Initially (1972-1976), no deer were intentionally removed from the enclosure; however, to ensure a stable population, the number of individuals within the enclosure was maintained at approximately 40 individuals with the removal of most fawns and older individuals each year starting in 1977 (Ozoga and Verme 1982). Although some potential bias could result from the removal of such individuals, in a natural population, most mortality would occur among 
the removed age classes (i.e., young and old individuals). Therefore, we assume the conditions within the enclosure are representative of a natural population, and in fact, the ages of mothers observed in this study (i.e., 1 to 13 years of age) falls within the natural range of breeding females (e.g., ages of pregnant deer darted in Alabama ranged from 1 to 13 year of age as determined by annuli in the cementum; S. T. Saalfeld, unpublished data).

A complete population census was obtained annually in March by live-trapping deer and placing them in a holding pen. At this time, all deer were marked with numbered collars and weighed. In addition, adult does were $\mathrm{X}$-rayed to determine stage of pregnancy and number of fetuses (Ozoga and Verme 1982). Age of fetuses was determined by comparing fetal radiograms with known-age fetal specimens (105 specimens ranging from 76 to 137 days old) determined by observed breeding dates (Ozoga and Verme 1985). Following this, birth dates were ascertained by using a 199-day gestation. Accuracy of this procedure was assessed by comparing predicted dates with known birth dates for 90 litters, and was found to be accurate within 3 days in $50 \%$ of litters, within 5 days in $66 \%$ of litters, and within 9 days in $93 \%$ of litters (Ozoga and Verme 1985). This variability fell within the natural variation expected in gestation times of well-nourished females (i.e., 196-213 days; Ozoga and Verme 1985). Pregnancy in fawns was also monitored at this time. Since fetuses within fawns would be too small to be detected on radiograms due to late conception dates, the presence of pregnancy in fawns was monitored through progesterone assay in peripheral plasma (Plotka et al. 1977).

Following the above procedures, deer were released back into a holding pen where they could be observed to confirm mother-fawn lineage from the previous year in some instances. Although most fawns were captured and tagged whenever possible within the enclosure to identify their mother, some were not captured until the March census. Therefore, observations at this time were used to either confirm or determine motherfawn lineage as well as to document the dominance hierarchy among the deer. The dominance number assigned to each individual corresponded to the percentage of the herd that the individual dominated while inside the holding pen. Dominance was determined by observing interactions at feeding stations and recording the number of individuals dominated by a particular individual. All deer were released from the holding pen in late March or early April, and thereafter, observations were used to further elucidate behavioral patterns, social habits, birthing periods, rearing success, and sex of offspring. Fawns were captured and tagged whenever the opportunity arose and therefore most were already identified prior to the following March census. Those that were not tagged by the March census were identified and tagged for visual identification at this time (Ozoga and Verme 1982). All research was performed in a humane manner, followed ASM guidelines, and was approved by an institutional animal care and use committee.

In order to determine any possible role of birth date on offspring sex ratio we analyzed data similar to Smallwood and Smallwood (1998). We subdivided fetuses into 10-day intervals for the range of birth dates determined from fetal radiograms in this study (13 May-25 July). Since not all groups had adequate sample sizes (Figure 1), we pooled data of groups with samples sizes less than 10 litters. This resulted in the pooling of dates after 22 June. We then tested whether sex ratios differed among these groups using repeated measures analysis of variance repeated among years with a compound symmetric covariance structure and birthing group nested within year as our error term (PROC MIXED: SAS Institute 1999). In addition, to determine differences in physical condition by birth date between sexes, we tested if mass of fawns measured the following spring (March) differed among birthing groups (e.g., birth date) within each sex using the same repeated measures analysis of variance. To test the validity of maternal-condition-based hypotheses within this population, we investigated if any difference existed among maternal condition (i.e., body mass and dominance) or age for females that produced male or female fawns using repeated measures analysis of variance repeated among years with a compound symmetric covariance structure. Although we were unable to account for repeatedly sampling females, we tested whether sex ratios among the different birthing periods differed from equality using a Pearson chisquare.

\section{Results}

A total of 428 fawns from 251 litters was examined during the study from fetal radiograms: mean birth date was 4 June ( $n=230 ; \mathrm{SE}=0.63$ days), and mean number of fawns per doe was $1.85(n=230$; $\mathrm{SE}=0.04)$. The offspring sex ratio $(50.4 \%)$ for the entire study did not differ from equality $\left(\chi^{2}=0.02\right.$; $P=0.880)$. We detected a difference $(F=2.86$; $P=0.031$; Figure 2$)$ in the proportion of males born among time periods, with a greater tendency of males being born in the second and fourth periods. We detected a greater proportion of males being born between 12 June and 21 June (70.4\%) than between 13 May and 22 May $\left(38.9 \% ; t_{58}=-2.30 ; P=0.025\right)$, 2 June and 11 June $\left(46.5 \% ; t_{58}=-2.78 ; P=0.007\right)$, and 22 June and 25 July $\left(38.9 \% ; t_{58}=2.11 ; P=0.040\right)$. We also found a tendency for more males being born between 23 May and 1 June (58.0\%) than between 2 June and 11 June, however only approaching significance $\left(t_{58}=1.78 ; P=0.081\right)$. We found no differences among other time periods $(P>0.050)$. Additionally, we found that the second birthing period had a sex ratio different than equality $\left(\chi^{2}=3.93 ; P=0.047\right)$. 


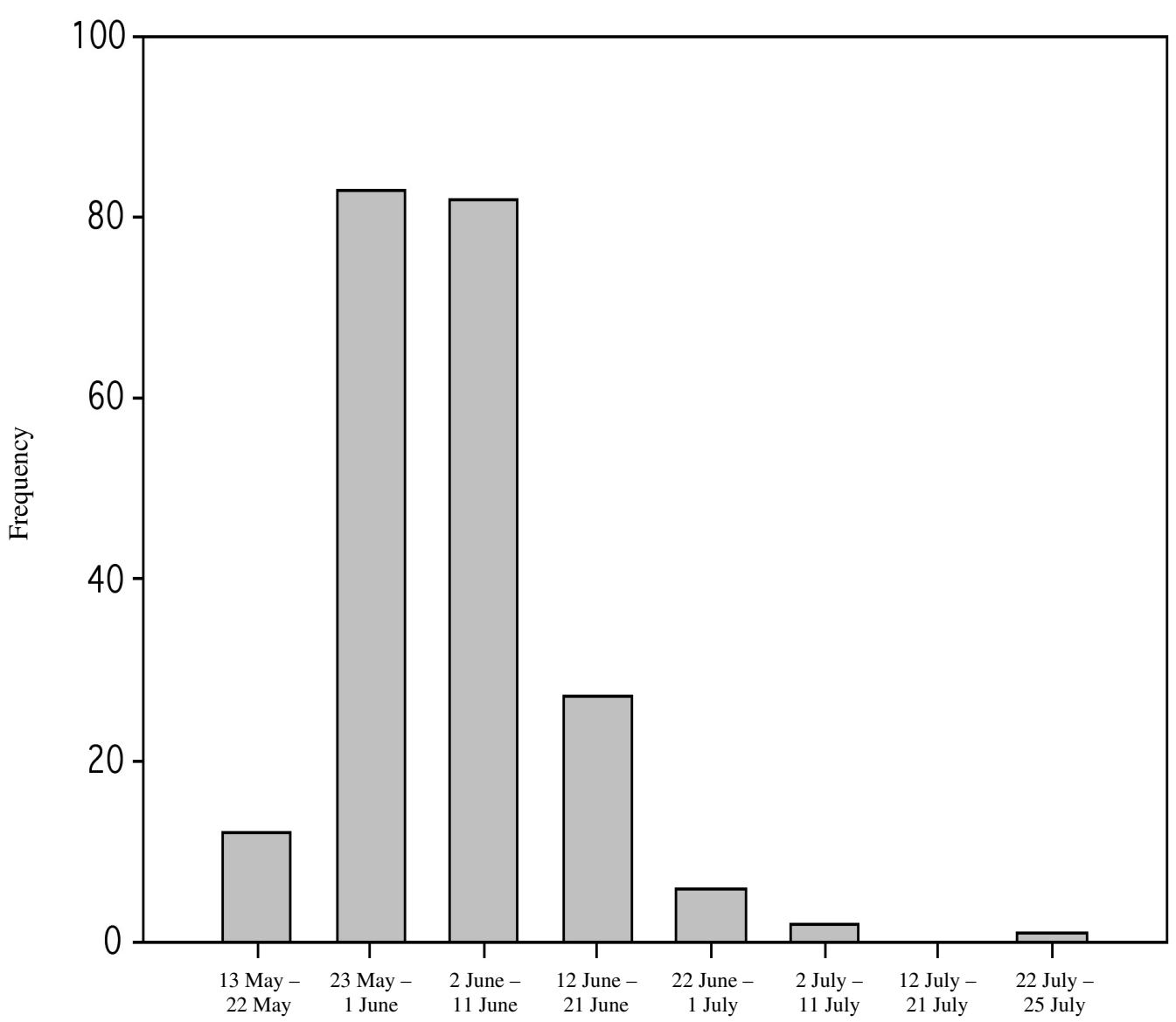

FIGURE 1. Frequency of White-tailed Deer litters in relationship to birth date from 1973 to 1984 (excluding 1974) at the Cusino deer research facility, Michigan, USA.

Body mass of fawns when approximately 9 months of age decreased as birth date became later for males $\left(F_{4,31}=5.11 ; P=0.003\right)$, but not for females $\left(F_{4,30}=\right.$ 1.94; $P=0.130$; Figure 3$)$. We also did not detect any differences between body mass $\left(t_{57}=1.60 ; P=\right.$ $0.211)$, dominance $\left(t_{56}=0.00 ; P=0.973\right)$, or age $\left(t_{57}=0.62 ; P=0.434\right)$ among mothers who produced either males or females.

\section{Discussion}

Our results support our hypothesis that offspring sex ratios differ based on birth date in White-tailed Deer. However, we found only moderate support for our hypothesis that more male offspring would be produced earlier in the birthing season as compared to females. Although we were unable to detect a significant difference in the sex ratios of the earliest birthing periods, we did find that more males tended to be born in the second birthing period resulting in a sex ratio different from parity. Although we found only a partial trend for this hypothesis, this trend has been demonstrated in other studies of White-tailed Deer, where it was found that more male offspring were likely to be conceived earlier in the birthing season (S. S. Ditchkoff, unpublished data; W. V. Underwood, unpublished data). In ungulates in a natural environment, individuals that are born earlier have more time to grow and access to more food than late-born conspecifics (FestaBianchet 1988; Singh et al. 1990; Festa-Bianchet et al. 1997; Côté and Festa-Bianchet 2001). While an earlier birth could be beneficial to both sexes, fitness gain would potentially be greater for males than females in a sexually dimorphic, polygynous species. Increases in body size and quality have been shown to strongly influence a male's initial reproductive success and lifetime fitness (Suttie 1983; Clutton-Brock et al. 1984; Kruuk et al. 1999; Festa-Bianchet et al. 2000). In addition, early births have also been shown to increase antler quality (Ozoga and Verme 1982; Schmidt et al. 2001; Gray et al. 2002), a trait which strongly affects 
dominance and ultimately reproductive success in ungulates (Clutton-Brock and Albon 1980; Bowyer 1986). Also, postweaning male fawns have a greater dietary protein requirement than females (Ullrey et al. 1967). Therefore, being born earlier would be most beneficial for males, since earlier born individuals have better food availability than late born individuals. Female fitness, however, is not as strongly influenced by this initial disadvantage in body size. Jorgenson et al. (1993) found that condition in female Bighorn Sheep (Ovis canadensis) did not have a major effect on age at first reproduction. However, they did detect a minimum mass for young ewes to begin reproduction. Variation in mass above this minimum, however, did not effect age at first reproduction. Therefore, producing a particular sex at a certain time has an adaptive advantage for a mother which ultimately increases her lifetime fitness.

In White-tailed Deer, most births normally occur within a short time period (e.g., several weeks). For example, $61 \%$ of litters in our population were born during a 15 day period (28 May - 11 June). We expect that in species that have a much longer birthing period or multiple litters within a year, seasonal sex ratio biases would be more prominent. This is true in Virginia Opossums (Didelphis virginiana: Wright et al. 1995), Meadow Voles (Microtus pennsylvanicus: Dobson and Myers 1989), and Gray-tailed Voles (Microtus canicaudus: Bond et al. 2003), and this pattern has been termed the first-cohort advantage hypothesis (Wright et al. 1995). In Virginia Opossums, females had more male-biased first litters than second litters, possibly due to the increased reproductive fitness of males born earlier (Wright et al. 1995). Additionally, in Meadow Voles, more male-biased litters were born earlier in the season than later, corresponding to a similar pattern in litter size, which also declined as the season progressed (Dobson and Myers 1989). On the other hand, Bond et al. (2003), when examining Graytailed Voles, found female-biased litters rather than male-biased litters early in the season. They hypothesized that this trend was seen since females almost always reproduce their first year, while most late-born males delay first breeding until the following spring. Additionally, they speculated that winter survival could also influence Gray-tailed Vole sex ratios, where males born later had greater survival through winter than females born at the same time. However, this does not discount the importance of seasonal sex-ratio variation in a species like White-tailed Deer where births are highly synchronized. Our data demonstrate the relative importance of birth dates on female and male condition the following spring in White-tailed Deer. Males born in the earliest birthing period had $18.1 \%$ greater mass the following spring at 9 months of age than males born in the last birthing period. Early-born females also tended to have greater mass the following spring than late-born individuals, but the difference between the groups was less $(9.7 \%)$. Since our study was conducted on a supplementally fed population, we suspect these differences to be less than in a natural population, where food would be limited during the winter months. Although these data do not measure future fitness, they provide strong support for the hypothesis that birth date differentially influences future fitness in males and females, as has been demonstrated in a number of avian species (Smallwood and Smallwood 1998; Pen et al. 1999; Cordero et al. 2001; Byholm et al. 2002; Griggio et al. 2002; Andersson et al. 2003; McIntosh et al. 2003). Despite this apparent trend, we did not detect a larger proportion of males born during the earliest time period. Although we are unsure of the specific reason for this, we suspect that early in the season, resource availability may be unpredictable. While giving birth early has advantages, it could also have disadvantages if food is unavailable or unpredictable at this time. Therefore, it may not be advantageous for females to invest in the more costly sex (i.e., males) if they may not be able to provide adequate nutrition for them. Low sample size during this time period $(n=12)$ could also have prevented us from detecting this trend.

Another interesting trend seen in our data was that more males were additionally born later in the season. This trend was also seen in American Kestrels, where more male-biased broods were born later in the season, although low sample size precluded statistical analysis (Smallwood and Smallwood 1998). Giving birth late in the season increases the likelihood of producing smaller, disadvantaged offspring of either sex. In Elk (Cervus elaphus nelsoni: Smith and Anderson 1998), Red Deer (C. elaphus: Clutton-Brock et al. 1987), and Moose (Alces alces: Keech et al. 2000) offspring of either sex that were late-born had decreased survival and reproduction. We propose that the best evolutionary strategy for a mother that conceives late may be to produce the dispersing sex. According to the local resource competition hypothesis (Clark 1978), a mother improves her own fitness, as well as that of previous and future offspring that reside within her home range, by producing the dispersing sex, which, by leaving, reduce competition for resources. Our data support this hypothesis, since both males and females born late in the birthing season had low mass the following spring compared to offspring born early. Despite this trend, we were unable to detect a greater proportion of males produced in the last time period, possibly due to the low sample size (9 litters).

Differing sex ratios according to birth date is an overlooked but perhaps very important tactic for increasing lifetime fitness of White-tailed Deer and other polygynous mammals. Although this is not the first documented evidence of seasonal variation in sex ratios in ungulates (Clutton-Brock et al. 1982; Kohlmann 1999) or large sexually dimorphic mammals (Coulson and Hickling 1961; Stirling 1971), we believe our data 


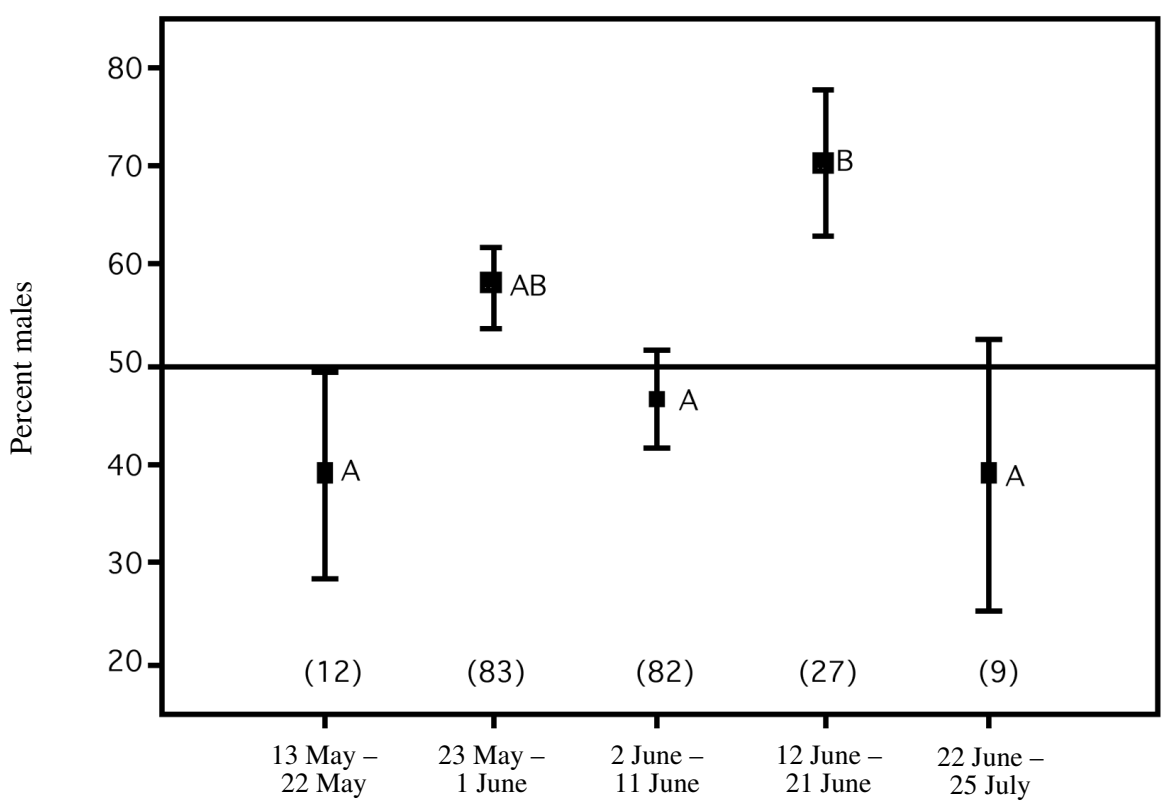

FIGURE 2. Litter sex ratio of White-tailed Deer offspring in relationship to birth date from 1973 to 1984 (excluding 1974) at the Cusino deer research facility, Michigan, USA. Means with the same letters are not different $(P>0.05)$. Numbers correspond to sample sizes of litters in each time period.

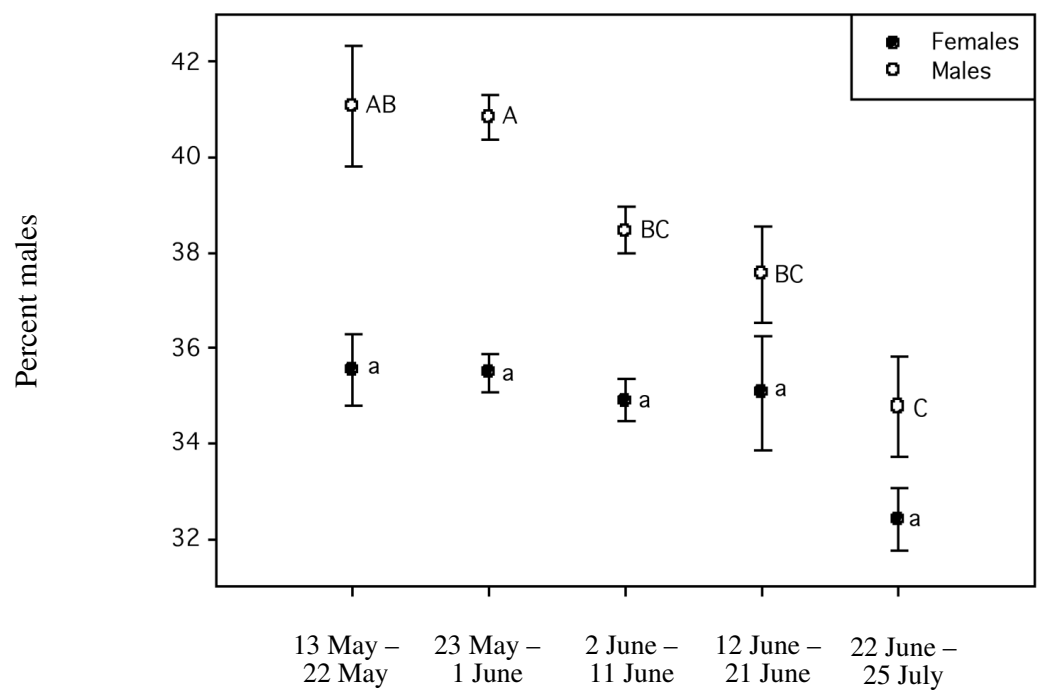

FIGURE 3. Mass of 9-month old male and female White-tailed Deer fawns born in relationship to birth date from 1973 to 1984 (excluding 1974) at the Cusino deer research facility, Michigan, USA. Means with the same letters within an age class are not different $(P>0.05)$. 
provides a better explanation for this phenomenon than has previously been proposed. Although there are numerous factors that influence sex ratios and timing of birth, it appears that timing of birth was the main cause of variation in sex ratios in the population we studied. Although our data were collected from a captive herd of White-tailed Deer, we assume that they are representative of a natural population, and since food was provided year round and a stable population was ensured, we expect some of the trends we have noted to be more dramatic in a natural population. This seasonal variation would be most beneficial in species where reproductive success is correlated with initial body mass and therefore birth date of a particular sex. This initial advantage for one sex may be based on a variety of life history traits that differentially affect one sex more than the other such as in sexually dimorphic, polygynous species that exhibit sex-biased competition for mates or territories.

\section{Acknowledgments}

We thank all of the individuals that assisted with data collection at the Cusino Enclosure during the time the research was conducted. This research was supported by the Center for Forest Sustainability and the School of Forestry and Wildlife Sciences at Auburn University, the Alabama Cooperative Fish and Wildlife Research Unit, and the Michigan Department of Natural Resources.

\section{Literature Cited}

Andersson, M., J. Wallander, L. Oring, E. Akst, J. M. Reed, and R. C. Fleischer. 2003. Adaptive seasonal trend in brood sex ratio: test in two sister species with contrasting breeding systems. Journal of Evolutionary Biology 16: $510-515$.

Bond, M. L., J. O. Wolff, and S. Krackow. 2003. Recruitment sex ratios in gray-tailed voles (Microtus canicaudus) in response to density, sex ratio and season. Canadian Journal of Zoology 81: 1306-1311.

Bowyer, R. T. 1986 . Antler characteristics as related to socialstatus of male southern mule deer. Southwestern Naturalist 31: 289-298.

Byholm, P., J. E. Brommer, and P. Saurola. 2002. Scale and seasonal sex-ratio trends in northern goshawk Accipiter gentilis broods. Journal of Avian Biology 33: 399-406.

Christley, R. M., K. L. Morgan, T. D. H. Parkin, and N. P. French. 2003. Factors related to the risk of neonatal mortality, birth-weight and serum immunoglobulin concentration in lambs in the UK. Preventive Veterinary Medicine 57: 209-226.

Clark, A. B. 1978. Sex ratio and local resource competition in a prosimian primate. Science 201: 163-165.

Clutton-Brock, T. H., and S. D. Albon. 1980. Antlers, body size and breeding group size in the Cervidae. Nature 285: 565-567

Clutton-Brock, T. H., S. D. Albon, and F. E. Guinness. 1984. Maternal dominance, breeding success and birth sex ratios in red deer. Nature 308: 358-360.

Clutton-Brock, T. H., F. E. Guinness, and S. D. Albon. 1982. Red deer: behavior and ecology of two sexes. University of Chicago Press, Chicago.
Clutton-Brock, T. H., M. Major, S. D. Albon, and F. E. Guinness. 1987. Early development and population dynamics in red deer. I. Density-dependent effects on juvenile survival. Journal of Animal Ecology 56: 53-67.

Cordero, P. J., J. Viñuela, J. M. Aparicio, and J. P. Veiga. 2001. Seasonal variation in sex ratio and sexual egg dimorphism favouring daughters in first clutches of the Spotless Starling. Journal of Evolutionary Biology 14: 829-834.

Côté, S. D., and M. Festa-Bianchet. 2001. Birthdate, mass and survival in mountain goat kids: effects of maternal characteristics and forage quality. Oecologia 127: 230-238.

Coulson, J. C., and G. Hickling. 1961. Variation in the secondary sex-ratio of the grey seal Halichoerus grypus (Fab.) during the breeding season. Nature 190: 281.

Dobson, F. S., and P. Myers. 1989. The seasonal decline in the litter size of meadow voles. Journal of Mammalogy 70 : 142-152.

Festa-Bianchet, M. 1988. Birthdate and survival in bighorn lambs (Ovis canadensis). Journal of Zoology 214: 653661

Festa-Bianchet, M., J. T. Jorgenson, C. H. Bérubé, C. Portier, and W. D. Wishart. 1997. Body mass and survival of bighorn sheep. Canadian Journal of Zoology 75: 13721379 .

Festa-Bianchet, M., J. T. Jorgenson, and D. Réale. 2000. Early development, adult mass, and reproductive success in bighorn sheep. Behavioral Ecology 11: 633-639.

Gray, W. N., II, S. S. Ditchkoff, M. K. Causey, and C. W. Cook. 2002. The yearling disadvantage in Alabama deer: effect of birth date on development. Proceedings of the Annual Conference of the Southeastern Association of Fish and Wildlife Agencies 56: 255-264.

Griggio, M., F. Hamerstrom, R. N. Rosenfield, and G. Tavecchia. 2002. Seasonal variation in sex ratio of fledgling American Kestrels: a long term study. Wilson Bulletin 114: 474-478

Hewison, A. J. M., and J. M. Gaillard. 1999. Successful sons or advantaged daughters? The Trivers-Willard model and sex-biased maternal investment in ungulates. Trends in Ecology and Evolution 14: 229-234.

Hiraiwa-Hasegawa, M. 1993. Skewed birth sex ratios in primates: should high ranking mothers have daughters or sons? Trends in Ecology and Evolution 8: 395-400.

Johns, P. E., R. Baccus, M. N. Manlove, J. Pinder, III, and M. H. Smith. 1977. Reproductive patterns, productivity and genetic variability in adjacent white-tailed deer populations. Proceedings of the annual conference Southeastern Association of Fish and Wildlife Agencies 31: 167-172.

Jorgenson, J. T., M. Festa-Bianchet, M. Lucherini, and W. D. Wishart. 1993. Effects of body size, population density, and maternal characteristics on age at first reproduction in bighorn ewes. Canadian Journal of Zoology 71: 2509-2517.

Keech, M. A., R. T. Bowyer, J. M. Ver Hoef, R. D. Boertje, B. W. Dale, and T. R. Stephenson. 2000. Life-history consequences of maternal condition in Alaskan moose. Journal of Wildlife Management 64: 450-462.

Kohlmann, S. G. 1999. Adaptive fetal sex allocation in elk: evidence and implications. Journal of Wildlife Management 63: 1109-1117.

Kojola, I., and E. Eloranta. 1989. Influences of maternal body weight, age and parity on sex ratio in semidomesticated reindeer (Rangifer t. tarandus). Evolution 43: 13311336. 
Kruuk, L. E. B., T. H. Clutton-Brock, K. E. Rose, and F. E. Guinness. 1999. Early determinants of lifetime reproductive success differ between the sexes in red deer. Proceedings of the Royal Society of London. Series B: Biological Sciences 266: 1655-1661.

Kucera, T. E. 1991. Adaptive variation in sex ratios of offspring in nutritionally stressed mule deer. Journal of Mammalogy 72: 745-749.

Landete-Castillejos, T., A. Garcia, S. Langton, I. Inglis, L. Gallego, and J. Garde. 2001. Opposing offspring sex ratio variations with increasing age and weight in mouflon mothers (Ovis musimon). Acta Veterinaria Hungarica 49: 257-268.

Landete-Castillejos, T., C. Gortázar, J. Vicente, Y. Fierro, A. Garcia, and L. Gallego. 2004. Age-related foetal sex ratio bias in Iberian red deer (Cervus elaphus hispanicus): are male calves too expensive for growing mothers? Behavioral Ecology and Sociobiology 56: 1-8.

Leimar, O. 1996. Life-history analysis of the Trivers and Willard sex-ratio problem. Behavioral Ecology 7: 316-325.

McIntosh, R. R., R. Kats, M. Berg, J. Komdeur, and M. A. Elgar. 2003. Breeding ecology and bias in offspring sex ratio in Little Grassbirds (Megalurus gramineus). Australian Journal of Zoology 51: 505-514.

Mendl, M., A. J. Zanella, D. M. Broom, and C. T. Whittemore. 1995. Maternal social status and birth sex ratio in domestic pigs: an analysis of mechanisms. Animal Behaviour 50: 1361-1370.

Ozoga, J. J., and L. J. Verme. 1982. Physical and reproductive characteristics of a supplementally-fed white-tailed deer herd. Journal of Wildlife Management 46: 281-301.

Ozoga, J. J., and L. J. Verme. 1985. Determining fetus age in live white-tailed does by X-ray. Journal of Wildlife Management 49: 372-374.

Pen, I., F. J. Weissing, and S. Daan. 1999. Seasonal sex ratio trend in the European Kestrel: an evolutionarily stable strategy analysis. The American Naturalist 153: 384397.

Plotka, E. D., U. S. Seal, L. J. Verme, and J. J. Ozoga. 1977. Reproductive steroids in the white-tailed deer (Odocoileus virginianus borealis). II. Progesterone and estrogen levels in peripheral plasma during pregnancy. Biology of Reproduction 17: 78-83.
SAS Institute. 1999. SAS/STAT software: the logistic procedure, version 8. SAS Institute, Cary, North Carolina, USA.

Schmidt, K. T., A. Stien, S. D. Albon, and F. E. Guinness. 2001. Antler length of yearling red deer is determined by population density, weather and early life-history. Oecologia 127: 191-197.

Sheldon, B. C., and S. A. West. 2004. Maternal dominance, maternal condition, and offspring sex ratio in ungulate mammals. The American Naturalist 163: 40-54.

Singh, D. K., H. R. Mishra, and C. S. P. Singh. 1990. Genetic and non-genetic factors affecting pre-weaning survivability in kids. Animal Production 51: 559-564.

Smallwood, P. D., and J. A. Smallwood. 1998. Seasonal shifts in sex ratios of fledgling American Kestrels (Falco sparverius paulus): the Early Bird Hypothesis. Evolutionary Ecology 12: 839-853.

Smith, B. L., and S. H. Anderson. 1998. Juvenile survival and population regulation of the jackson elk herd. Journal of Wildlife Management 62: 1036-1045.

Stirling, I. 1971. Variation in sex ratio of newborn Weddell seals during the pupping season. Journal of Mammalogy 52: 842-844.

Suttie, J. M. 1983. Body size: dominance relationships in red deer stag calves. Animal Behaviour 31: 610-611.

Trivers, R. L., and D. E. Willard. 1973. Natural selection of parental ability to vary the sex ratio of offspring. Science 179: 90-92.

Ullrey, D. E., W. G. Youatt, H. E. Johnson, L. D. Fay, and B. L. Bradley. 1967. Protein requirement of white-tailed deer fawns. Journal of Wildlife Management 31: 679-685.

Verme, L. J. 1983. Sex ratio variation in Odocoileus: a critical review. Journal of Wildlife Management 47: 573-582.

Verme, L. J., and J. J. Ozoga. 1981. Sex ratio of white-tailed deer and the estrus cycle. Journal of Wildlife Management 45: 710-715.

Wright, D. D., J. T. Ryser, and R. A. Kiltie. 1995. Firstcohort advantage hypothesis: a new twist on facultative sex ratio adjustment. American Naturalist 145: 133-145.

Received 10 August 2007

Accepted 29 August 2008 